\title{
Translation, Cultural Adaptation and Validation of The Caregiver Well-Being Scale (CWBS) in Iranian Schizophrenia Caregivers: A Methodological and Cross-Sectional Study
}

\section{Shahpar Bagheri}

Shiraz University of Medical Sciences

Ladan Zarshenas ( $\sim$ zarshenasster@gmail.com )

Shiraz University of Medical Sciences

Mahnaz Rakhshan

Shiraz University of Medical Sciences

Farkhondeh Sharif

Shiraz University of Medical Sciences

Ebrahim Moghimi Sarani

Shiraz University of Medical Sciences

\section{Zahra Hadian Shirazi}

Shiraz University of Medical Sciences

\section{Research Article}

Keywords: Caregivers, CWBS, Psychometrics, Schizophrenia, Validation, well-being

Posted Date: December 4th, 2020

DOl: https://doi.org/10.21203/rs.3.rs-113686/v1

License: (c) (1) This work is licensed under a Creative Commons Attribution 4.0 International License.

Read Full License 


\section{Abstract}

Background: Family caregivers of individual with schizophrenia experience various stresses in everyday life which have a negative impact on their well-being. The Caregiver Well-Being Scale(CWBS) is an instrument with psychometrics properties that identifies many important factors associated with caregiving stressors, and provides a picture of overall felt well-being. Since, there is no Persian version of this instrument for investigating schizophrenia caregiver's well-being, cross cultural adaptation and evaluation of the psychometric properties of the CWBS among Iranian Schizophrenia caregivers is required.

Methods: A methodological and cross-sectional study was conducted with 144 Schizophrenia caregivers in psychiatric centers affiliated to Shiraz University of Medical Sciences(SUMS), in the south of Iran. Persian version of the CWBS was generated in two phases: Phase 1 - Cross-cultural adaptation using forward translation and backward translation methods in five stages. Phase 2 - Psychometric properties test involved assessing content validity, construct validity by exploratory factor analysis and convergent and divergent validity, reliability by internal consistency and test -retest.

Results: The translation, cross-cultural adaptation and qualitative content validity resulted in some semantic modifications to the original CWBS version. Both subscales of CWBS -(Basic Need(BN) and Activities of Daily living (ADL)- showed a significant strong positive correlation with total CWBS, (BN: $r=$ 0.81 and ADL: $r=0.88)$, moderate positive correlation with SOC (BN: $r=0.42$ and ADL: $r=0.46)$, and moderate negative correlation with $\mathrm{CBI}(\mathrm{BN}: \mathrm{r}=-0.38$ and $\mathrm{ADL}$ : $r=-0.47)($ all $p<0.001)$, presenting convergent and divergent validity. Factor analysis and Varimax Rotation provide evidence that the Persian version encompasses three underlying constructs for $A D L$ and $B N$, as the original scale. The CWBS showed acceptable internal consistency (Cronbach's alpha: 0. 0.842) and satisfactory test-retest reliability within 2.5 weeks interval (intraclass correlation coefficient was 0.872 ( $95 \%$ confidence interval [Cl], 0.827 to 0.906$)$ ) for 14 items.

Conclusions: The results showed the Persian adapted version of CWBS complies the validity and reliability of the criteria required. The scale can be employed in practice and research to assess well-being in Iranian caregivers of individuals with schizophrenia.

Registration number: (registration no.97-01-08-18819).

\section{Introduction}

Schizophrenia is a complex psychotic disorder $(1,2)$ that makes patients highly dependent on their caregivers $(3,4)$ thus heavy humanistic burden of schizophrenia disease has impacts not only on patients' health and well-being but also on their caregivers(5). Schizophrenia caregivers who are often family members face many difficult situations during caring for their patients. They experience various stresses in everyday life and they have to give up their previous daily routine activities(6). Health professionals should consider caregivers' needs and challenges and prepare supportive resources for promoting their 
health and well-being(7). Outcome measurements are essential to monitoring and improving an individual's health outcomes and they also assess effectiveness of health care intervention(8). Studies on schizophrenia caregivers include an overuse of measures about negative aspects of caregiving such as burden while both the positive and the negative aspects of clients' caregivers should be considered(9). The Caregiver Well-Being Scale(CWBS) is an instrument with psychometrics properties (10) and helps to recognize both positive and negative aspects of caregiving and also helps caregivers become more in touch with their own abilities. CWBS helps health professionals to advocate caregivers in coping with stress by Identifying resources, and revealing the deficient parts (11). Several studies were administered CWBS for assessing and treating the well-being of caregivers of patients with chronically ill such as Alzheimer disease and related dementia(12-23). However, this instrument has not been yet validated for use in caregivers of people with schizophrenia in Iran. It is certain that Using an instrument in a different country by people who speak a different language, necessitates the translation and cultural adaptation of the instrument(24). Therefore, since the original instrument is in English language and the scale has not been culturally or linguistically adapted for Iranian population, there is no Persian version of this instrument for investigating schizophrenia caregivers' well-being.

Thus, there is a clear need to cross cultural translation and re-examine the psychometric properties of the CWBS by focusing on caregivers for individuals with schizophrenia in order to extend the applicability of this questionnaire to the Iranian population. The objective of this study was to translate and evaluate the psychometric properties of the CWBS among a sample of Iranian caregivers of individuals with a diagnosis of Schizophrenia. Such research has the potential to contribute to the existing knowledge on the topic and will provide the CWBS instrument to be used by healthcare professionals as well as researchers to evaluate the well-being of schizophrenia caregivers and promote their health. In conclusion, this study might help enhance the understanding of well-being of schizophrenia caregivers and improve their health status.

\section{Methods}

\section{Aims}

The purpose of the study was to translate and evaluate the psychometric properties of the CWBS among a sample of Iranian schizophrenia caregivers.

\section{Study design}

This cross-sectional, descriptive study was designed in two phases: Phase 1 - the translation and crosscultural adaptation of CWBS from English to Persian in I-V stages (involved scale forward translations, Synthesis the translations, back ward translations, reconciliation experts Committee and pre-testing of the translated Persian version through cognitive interview). Phase 2 - Psychometric properties test of CWBS in an Iranian schizophrenia caregiver population (involved assessing content and construct validity, internal consistency and reliability). This study was guided by the Measures translation, crosscultural adaptation and validation guidelines proposed by literatures(24-27). 


\section{Settings}

This study was conducted from Jun 2019 to May 2020 in all psychiatric centers (Ebnesina, Moharary and Hafez) affiliated to Shiraz University of Medical Sciences(SUMS), in the south of Iran.

\section{Participants}

To be eligible to participate in the study, participants were required to be: (1) over 18 years old, (2) able to understand and speak and write in Persian, (3) the main family caregiver of patients with schizophrenia for at least one year, (4) willing to participate. Exclusion criteria included: (1) unable to understand the study procedures, (2) people being treated for mental illness. The sample size was conducted following guidelines recommendations, with about 30-40 participant for the pre-test study in process of crosscultural adaptation and 10 participants per each item being the number most often recommended to validate instrument in field test(26). Thus a sample of 30 participants were recruited for testing of pre final version of CWBS. In view of the 14 items of the CWBS, 144 subjects were deemed reasonable in order to assess the psychometric properties of CWBS. Every participant received complete information about purpose of the study and data collection procedures. They were assured of anonymity and confidentiality.

\section{Ethical considerations}

The study was approved by the Institutional Human Ethics Committee of Shiraz University of Medical Sciences (IR.SUMS.REC.1398.574). All participants included in the study, signed an informed consent form on recruitment to the study. All procedures performed in this study were comply with the ethical standards of the institutional and national research committee and with the 1964 Helsinki declaration and its later amendments or comparable ethical standards.

\section{Measures}

\section{Caregiver Well-being Scale (CWBS)}

This scale identifies areas a caregiver may be lacking support, addresses many important factors associated with caregiving stressors, and provides a picture of overall well-being. CWBS -originally developed by Tebb (1995)- has 45-items in order to measure level of satisfaction on basic needs and level of daily activities as two critical areas to the well-being of caregivers while carrying out caregiving duties(11). Tebb (2013) et al. developed and validated the shortened form of CWBS that is easier to use than original form but it has the same goals. This instrument consists of 14 items in two subscales: (1) activities daily living(ADL) with 8 items and (2) basic human needs (BN) with 6 items. The activities of living subscale assess subjects' level of ability to perform those activities that are needed to meet their basic needs. The basic needs subscale measures the extent to which caregivers can meet their needs such as eating well. CWBS is answered on a 1 to 5 point Likert type scale. Higher scores indicate greater well-being among caregivers. The internal consistency reliability of the BN and ADL scales as measured by Cronbach's alpha were 0.73 and 0.74 respectively. Overall reliability coefficient of the CWBS was 0.83 
(22). We coordinated with professor Tebb, the author of the original CWBS, about the translation and cultural adaptation of the scale into Persian. The original and Persian version of the CWBS are attached in Supplementary material.

\section{The Caregiver Burden Inventory (CBI)}

The $\mathrm{CBI}$, as a self-report instrument, measures both objective burden and subjective burden among caregivers of patients with chronic diseases. It has 24 items in five Subscales: Time-Dependence Burden, Developmental Burden, Physical Burden, Social Burden, and Emotional Burden. Items are rated on a Likert scale from 0 to 4 . Higher scores indicate more bothersome burden among caregivers (28). A literature review shows that the internal consistency of the $\mathrm{CBI}$ is ranging from 0.92 to 0.94 . The Persian version of this scale has good psychotic properties and its reliability reported by a Cronbach's alpha coefficient is $0.90(29)$.

\section{Sense of coherence (SOC-13)}

The SOC scale was developed by Antonovsky (30) to measure the concept of sense of coherence. It is composed of comprehensible, manageable and meaningful components to assess coping with stress. The SOC-13 scale consists of 13 items, with each item ranging from 1 to 7 points. Higher scores indicate a greater ability to cope with stressful situations and maintain health. The reliability and validity of this scale have been tested by Eriksson and Lindström (31). The reliability and validity of the Persian version of SOC-13 have also been examined -the Cronbach's alpha were higher than $0.70(32,33)$.

\section{Statistical analysis}

Data analysis was carried out using SPSS-18 software (SPSS Inc., IL, USA). The normality of data was evaluated using Kolmogorov-Smirnov test. All tests were two-tailed and P-value 0.05 was considered significant.

\section{Results}

\section{Result of phase 1 (The Translation and adaptation Process of CWBS):}

\section{Stage l: forward translation}

This stage included the translation and cultural adaptation of the original CWBS from English to Persian to provide more equivalency and highlight ambiguous meanings in the original questionnaire; the CWBS translated by two bilingual translators who had different background or profiles (one PhD nurses, a professional translator with no medical or clinical background). Each translator, whose mother tongue was the Persian language, worked independently and they were blinded to the work of the other translator. They produced two translations. During the forward translation, some problematic words and phrases were identified. In the ADL dimension, there was difficulty translating item 5 (Participating in events at church and/or in the community), of the original version's Activities domain, "church", was 
translated into Persian as "amaken mazhabi [religious places]" by one translator and the other translator used "masjed [mosque]". However, the phrase "amaken mazhabi [religious places]" was retained by reached consensus between the two translators' reports, because the majority of people in Iran are Muslims and attend in events at mosque and other religious places.

\section{Stage II: Synthesis}

The two Persian versions were compared together. Ambiguities or poor wording in the original version was negotiated by the translators. The results of the translations were synthesized to produce the Persian version of the questionnaire by reached consensus between the two translators' reports.

\section{Stage III: Back Translation}

Direct translation of an outcome measure developed for one language or culture to another language may not result in a valid instrument. The questionnaire was translated back into the original language to make sure that the translation reflects the same item content as the original to semantic equivalence achievement. Backward translation was done independently by another two competent translators who were blind to the original English version, with no medical background and their first language was English. This step magnified unclear wording and imperfections in the translations. This was a process of validity checking to make sure that the translated version is equivalent in meaning for a consistent translation. Comparing two back-translations with each other and the original, showed no significant differences in meaning and the translations were recognized to be equal. The translated CWBS was then provided to the expert panel.

\section{Stage IV: Reconciliation Experts Committee}

The fourth step of the translation process was a final reconciliation with committee of experts to consolidate. This committee, was composed of researchers, a professional translator, a methodologist, and four translators reviewed all versions and reached a consensus on any discrepancy and verified the cross-cultural equivalence of the instrument. This stage was conducted to consolidate all the information from the previous translation stages to achieve cross-cultural equivalence between the source and target version in Semantic, idiomatic, experiential, conceptual. They discussed and reached a consensus on discrepancies and verified the cross-cultural equivalence of the instrument which led to the pre-final Persian version of the CWBS created.

\section{Stage V: Test of the Pre-Final Translated Version}

The pre-final version of CWBS was tested through cognitive face to face interview with a convenience sample of 30 participants who was representative of population age, sex and education level. During this step, the interviewer read each item. After which, participants answered to that item, they were asked about the comprehensibility, content, difficulty and ambiguousness with the item. They were given the opportunity to state their viewpoints and suggestions on items because they were familiar with the construct through deep personal experience. This stage resulted in modifications to two items of the 
original version. In ADL scale: Item 3 ("Attending to medical needs" was changed to the "Attending to medical needs (preventive and curative)); Item 8 ("Making plans for your financial future" was changed to "Making plans for your financial future (having job and/or income)". This stage provided insight into how a person interprets the items on the questionnaire ensured the linguistic and conceptual equivalence of the translation.

\section{Result of phase2}

The translated instrument tested for its psychometric characteristics.

\section{Participant characteristics}

Descriptive statistics including mean, frequency, and standard deviation (SD) were determined for all variables and were expressed as mean \pm SD for normally distributed variables. We invited 150 schizophrenia caregivers to participate in the study (six refused). Of the 144 participants included in the validation process, $75 \%$ were female. Participant ages ranged from 25 to 75 years with a mean of 52 (SD $=12.4)$. The majority of the sample had some college or higher education $(91 \%$ of the participants were educated. $31 \%$ were educated to diploma level. $77 \%$ were married, and they were most likely to be parents ( $40.3 \%$ were mothers) and had a mean of 3 children. The caregivers had provided care for a mean of almost 10 years.

\section{content validation (qualitative and quantitative content validity)}

This step aimed to assess content validity of the Persian version of the CWBS.

\section{Qualitative content validity}

Paying attention to content validity is critical step in assessing an instrument's validity because If the content of an instrument is an adequate reflection of a construct, then the instrument has a better chance in reaching its measurement objectives.(26) Content validity indicates how well the instrument has the appropriate items that comprise all important aspects of the construct being measured. Content validity is often measured by relying on the knowledge of relevant experts(26). To assess the qualitative content validity, a panel composed of 15 experts in the fields of mental health, who were familiar with the psychometric process, were asked to provide their views on the accuracy of the items' content in written form regarding its ease of use, wording, grammar, item allocation, and scaling. Some items from the original version were subjected to more clarification and modifications during qualitative content validity steps. In ADL scale: Item7 ("Treating or rewarding yourself" was changed to "Treating or rewarding yourself (doing favorite activities, relaxing, exercising, having a hobby, laughing, etc.)"). In BN scale: Item5 ("Feeling good about yourself" was changed to "Feeling good about yourself (feeling valuable, having purpose in life) "). Since the experts couldn't agree on clarifying item 4 "Having adequate shelter", the author was asked about it and item was changed to "Having adequate shelter (having a safe place to live in)". 


\section{Quantitative content validity}

Content validity ratio (CVR) and content validity index (CVI) were used to achieve the quantification content validity of this scale.

\section{CVR}

The content validity ratio (CVR) by Lawshe's method was used to evaluate whether each item was essential to determine the rejection or retention of items. Eleven experts were each asked to rate each item into one of three categories: (Essential = 3; useful, but not essential = 2, and not essential $=1$ ). Then, the CVR value was computed for each item in the following way: CVR= (Ne - N/2)/(N/2); Where, ne= the number of total experts in panel, $\mathrm{N}=$ the total number of experts judging an item 'essential' (2 and 3 ). Based on the Lawshe table(34), a CVR of at least 0.59 was considered acceptable. In this study result of CVR was 0.6 to 1.0. Further details are presented in Table 1.

Table 1.Result of CVR

\section{CWBS}

Items

CVR

DL 1. Buying food

2. Taking care of personal daily activities (meals, hygiene, laundry)

3.Attending to medical needs (preventive and curative)

4.Keeping up with home maintenance activities (lawn, cleaning, house repairs, etc.)

5- Participating in events at religious places and/or in the community

6- Taking time to have fun with friends and/or family

7- Treating or rewarding yourself (doing favorite activities, relaxing, exercising, having a hobby and laughing, etc.)

8- Making plans for your financial future (having job and /or income)

BN 1-Eating a well-balanced diet

2- Getting enough sleep

3- Receiving appropriate health care

4- Having adequate shelter(having a safe place to live in)

5- Feeling secure about your financial future

6- Feeling good about yourself (feeling valuable, having purpose in life) 
computed by CVI. The CVI is the mean of the CVR values of the retained items. The scale was given to the experts' panel in order to determine the CVI. They separately assessed the items in the Persian version using a 4-point Likert scale for relevancy and rated each item from 1 to 4 for relevancy. 2 types of CVI can be computed using: 1 ) the individual-content validity index (I-CVI), and 2) the scale content validity index $(\mathrm{S}-\mathrm{CVI})$. To determine the relevancy of each item I-CVI calculation was conducted using the proportion of experts who rated the items as highly relevant and quite relevant, (a rating of 3 or 4 ). I- CVI values ranged from 0 to 1 where above 0.79 , the items were adequately relevant and were regarded acceptable. If an item scored between 0.70 and 0.79 , then it is somewhat relevant, its relevancy is questionable and the item needs to be revised and if the value is below 0.70 , the item is not relevant and is deleted(35). In this study all items had ICVI $=1.00$ thus, they were considered relevant.

CVI

$\mathrm{S}-\mathrm{CVI}$ is calculated using the number of items in a scale that has achieved a rating of "highly or quite relevant" by experts. There are two different approaches to determine S-CVI, (the S-CVI/Ave being a less conservative approach). Presenting both indices has been recommended(36) used to calculate S-CVI: 1(S-CVI/UA) are universal agreements by experts that calculated the proportion of the items in the scale that the experts valued as relevant, while 2- (S-CVI/Ave) is average agreement by experts. In the average approach, the sum of I-CVI in scale is divided by the total number of items. Researchers recommend that the acceptable standard for the S-CVI/UA and the S-CVI-Ave is above $0.8(27,36)$ and a value exceeding 0.90 is considered excellent(27). It is recommended that the researchers should mention the approach used for CVI computing because the values obtained from both approaches may be different (37) However, in this study S-CVI was conducted by both indices for all items obtained 1 . Thus, the values were considered excellent. Due to the possibility of a chance of agreement in the Content Validity Index, Polit et al., recommended propose Cohen's modified Kappa coefficient should be calculated. This coefficient is an index of appraiser agreement on the relevance of each item and provides the degree of agreement among experts beyond chance. Kapa coefficient above 0.75 is considered excellent, between 0.6-0.74 good and less than 0.59 weak. Therefore, Kappa coefficient was computed based on following formula: $\mathrm{K}=(\mathrm{I}-\mathrm{CVI}-\mathrm{PC}) /(1-\mathrm{Pc})$, where $\mathrm{Pc}=[\mathrm{N} ! / \mathrm{A} !(\mathrm{N}-\mathrm{A}) !]$ * $0.5 \mathrm{~N}(26,35)$. The kappa statistic values also obtained 1 because all items had received high relevancy scores by the experts.

\section{Constructs validity}

\section{Convert and divergent validity}

Pearson's correlation coefficient was used to evaluate the Inter-scale correlations(38). Convert and divergent validities were supported if correlation between BN and ADL with their hypothesized scale was higher than their correlation with the other scales. We considered levels classified as follows: less than 0.30 , weak correlation; between 0.30 and 0.50 , moderate correlation; and above 0.50 , strong correlation(39). As it was shown in table2., both subscales of CWBS showed a significant strong positive correlation with total CWBS (BN: $r=0.81$ and ADL: $r=0.88$ ), moderate positive correlation with SOC (BN: $r$ $=0.42$ and $A D L: r=0.46)$, and moderate negative correlation with $C B I(B N: r=-0.38$ and $A D L: r=-0.47)$, as 
expected. The correlation relationship between the BN and ADL and with its hypothesis scale (CWBS), was higher than their relationship with other scales.

Table 2.The inter scale correlation between ADL and BN with CWBS, CBI and SOC

\begin{tabular}{|llll|}
\hline & $\begin{array}{l}\text { Convergent } \\
\text { validity }\end{array}$ & \multicolumn{2}{l|}{$\begin{array}{l}\text { Divergent } \\
\text { validity }\end{array}$} \\
scales & Total & CBI & SOC \\
& CWBS & & \\
ADL & 0.88 & -0.47 & 0.46 \\
BN & 0.81 & -0.38 & 0.42 \\
\hline
\end{tabular}

\section{Exploratory factor analysis}

The exploratory factor analysis (EFA) was conducted to determine the construct validity of CWBS. An item would be retained if it was unique and sufficient by loading $>0.40$ or better $(26,39)$. Prior to exploratory factor analysis, The Kaiser-Meyer-Olkin (KMO) test of sampling adequacy was conducted and Bartlett test of sphericity was analyzed (26). The result of the KMO test of sampling adequacy was 0.781 , above the recommended valued of 0.6 and the result of the Bartlett test of sphericity was $\left(X^{2}=\right.$ 675.646 , and $d f=91, P<0.001$ ), indicating the factor ability of the correlation matrix suitability for factor analysis.

The items to total correlations and item loadings resulted from the factor analysis with Varimax rotation to test the construct validity of the subscales are presented in Table 3.

In the un-rotated solution, most items were loaded on a single factor. As a result, a three factor solution was done. In ADL, all items were loaded on to the same factors as scale developer report (2013) with accounting for $67 \%$ and $77 \%$ of the variance for $A D L$ and $B N$, respectively. In ADL all items loaded onto three factors with loadings higher than 0.40 , and the lowest and highest loadings were 0.557 (item 3 ) and 0.833 (item2), respectively. In BN all items loaded onto three factors had factor loadings higher than 0.40 , and the lowest and highest loadings were 0.757 (item 1) and 0.951 (item5), respectively. The items of 'Feeling good about yourself' (item5), in BN scale, itself was a separate factor from other factors.

Table 3.Result of Exploratory factor analysis. 


\begin{tabular}{|c|c|c|c|c|c|}
\hline & \multirow[t]{2}{*}{ Item } & \multirow{2}{*}{$\begin{array}{l}\text { Item to } \\
\text { total } \\
\text { correlation }\end{array}$} & \multicolumn{3}{|c|}{ Factor loading } \\
\hline & & & Factor1 & Factor2 & Factor3 \\
\hline \multirow[t]{4}{*}{ Self-Care } & Buying food & 0.598 & 0.779 & & \\
\hline & $\begin{array}{l}\text { Taking care of personal daily } \\
\text { activities (meals, hygiene, laundry) }\end{array}$ & 0.577 & 0.833 & & \\
\hline & $\begin{array}{l}\text { Attending to medical needs } \\
\text { (preventive and curative) }\end{array}$ & 0.671 & 0.557 & & \\
\hline & $\begin{array}{l}\text { Keeping up with home } \\
\text { maintenance activities (lawn, } \\
\text { cleaning, house repairs, etc.) }\end{array}$ & 0.695 & 0.712 & & \\
\hline \multirow[t]{2}{*}{ Connectedness } & $\begin{array}{l}\text { Participating in events at religious } \\
\text { places and/or in the community }\end{array}$ & 0.650 & & 0.824 & \\
\hline & $\begin{array}{l}\text { Taking time to have fun with } \\
\text { friends and/or family }\end{array}$ & 0.641 & & 0.804 & \\
\hline \multirow[t]{2}{*}{ Time for Self } & $\begin{array}{l}\text { Treating or rewarding yourself } \\
\text { (doing favorite activities, relaxing, } \\
\text { exercising, having a hobby and } \\
\text { laughing, etc.) }\end{array}$ & 0.648 & & & 0.735 \\
\hline & $\begin{array}{l}\text { Making plans for your financial } \\
\text { future (having job and/or } \\
\text { income) }\end{array}$ & 0.662 & & & 0.828 \\
\hline \multirow[t]{3}{*}{ Physical Needs } & Eating a well-balanced diet & 0.724 & 0.757 & & \\
\hline & Getting enough sleep & 0.661 & 0.886 & & \\
\hline & Receiving appropriate health care & 0.720 & 0.787 & & \\
\hline \multirow[t]{2}{*}{ Self-Security } & $\begin{array}{l}\text { Having adequate shelter(having a } \\
\text { safe place to live in) }\end{array}$ & 0.710 & & 0.784 & \\
\hline & $\begin{array}{l}\text { Feeling secure about your financial } \\
\text { future }\end{array}$ & 0.689 & & 0.854 & \\
\hline $\begin{array}{l}\text { Emotional } \\
\text { Needs }\end{array}$ & $\begin{array}{l}\text { Feeling good about yourself } \\
\text { (feeling valuable, having purpose in } \\
\text { life, etc.) }\end{array}$ & 0.625 & & & 0.951 \\
\hline
\end{tabular}

\section{Reliability}

Internal consistency was obtained using Cronbach's alpha. Internal consistency reliabilities for CWBS and its subscales were acceptable. The Cronbach's alpha was 0.79 and 0.77 for the ADL and BN dimension respectively and a total Cronbach's alpha of 0.842 for the items. To determine consistency and repeatability of the CWBS, test-retest reliability was computed for the stable group by using Intraclass 
Correlation Coefficient (ICC) and Pearson correlation coefficient. No information about the previous CWBS scores were provided to the study participants. Reliability coefficients over 0.70 were considered acceptable(40). In the test-retest analysis, the ICC was 0.794 (95\% confidence interval [Cl], 0.725 to 0.847 ) and 0.815 ( $95 \%$ confidence interval [Cl], 0.751 to 0.863 ) for the $A D L$ and $B N$ dimension respectively and for the total scale it was 0.872 (95\% confidence interval [CI], 0.827 to 0.906$)$. Mean time interval between the initial and second test was 2.5 weeks $(S D=0.69)$. These results demonstrated that there was not much variability between the test-retest of the CWBS. Although participants were not informed of their initial test scores, their responses in the retest indicated a high correlation, consistency and reliability.

\section{Discussion}

This is the first study with focus on translate and evaluating psychometric properties of the CWBS in a sample of Iranian Schizophrenia caregivers. The process of forward-backward blind translation was done to correct potential errors in translation that are known to affect reliability and validity in measurement. In this study, the scale was culturally adapted, and the comments and suggestions of the participants and specialists were used to produce the final version of CWBS. This study provides evidence for the need of cross-cultural adaptation after translation of a measure to the target language. For example, "church", of the original version's ADL domain, was proposed alternative Persian translation that means "religious places", because "church" is suitable in many countries where the majority of the population is Christian, but the majority of people in Iran attend events at varies religious places such as Mosques. In addition, in some items, clarifications and modifications were required that were made using previous articles and in consultation with the CWBS designer. For example, it was explained that the purpose of "medical needs" is preventive and curative activities, "Treating or rewarding yourself" was clarified with these examples: (doing favorite activities, relaxing, exercising, having a hobby and laughing, etc.), "Making plans for your financial future" was explained with (having job and income), "Feeling good about yourself" was explained with (feeling valuable, having purpose in life), and finally, "Having adequate shelter" was clarified with (having a safe place to live in).

The correlation relationship between the BN and ADL and with its hypothesis scale (CWBS), was higher than their relationship with other scales. The correlation relationship between the BN and ADL and with CWBS, is higher than their relationship with other scales, as well as, the result of convergent and divergent validity of original version(14) and Turkish version(41) of CWBS, would further indicate that this instrument has construct validity. Factor analysis and Varimax Rotationp provide evidence that the Persian version of the CWBS encompasses three underlying constructs for ADL, namely, Self-Care, Connectedness and Time for Self. And three underlying constructs for BN includes Physical needs, Emotion needs and Self-security. This is in agreement with the findings of psychometric properties testing of developer of this questionnaire - Based on the principal framework of the scale(22).

The Persian-version of CWBS showed an acceptable internal consistency reliability with a Cronbach's alpha value 0.842 for the total and 0.79 and 0.77 for the $A D L$ and $B N$ subscales, these values are above 
the suggested minimum of 0.70 , indicating that Persian-version instruments show reliability(40). The English version, however, reported weaker internal consistency coefficients, with a Cronbach's alpha value 0.83 for the total and 0.74 for the ADL subscale and 0.73 for the BN subscale(22). On the long version, Cronbach's alpha was 0.81 for the ADL dimension, .91 for the BN dimension, and 0.83 overall (14). Also in Turkish version, the internal consistency reliabilities of the basic needs subscale and activities of living subscale were .93 and .89 , respectively. The Cronbach Alpha value of the total scale was $0.93(41)$. The finding of the current study demonstrated an excellent test-retest reliability (ICC $=0.872)$. We followed up participants in the current study after 2.5 weeks, as recommended in the literature for the test-retest reliability, which is long enough to avoid recall bias. The scale also was demonstrated a strong test-retest reliability $(r=.79, p<.001)$ in Turkish version (41).

It is recommended that psychometric properties of the scale should be evaluated based on larger samples size in different cultures and in caregivers of other diseases in future studies to improve the power of this questionnaire. One of the strengths of this study was sampling that it had maximum diversity in sampling with varies demographic properties to more representative the target group.

In conclusion, the study results suggest that the Persian-version CWBS is a reliable and valid instrument for assessing well-being in Iranian schizophrenia caregivers. Finally, as the scale developer has emphasized, it is hoped that researchers and clinicians could use the CWBS to investigate the caregiver's basic human needs and activities, identify areas of caregivers' strength and areas in which additional support is needed for a healthy life and improve their well-being.

\section{Abbreviations}

CWBS: Caregiver Well-Being Scale; BN: Basic Need; ADL: Activities of Daily living; SOC: Sense of coherence; $\mathrm{CBI}$ : Caregiver Burden Inventory.

\section{Declarations}

\section{Acknowledgement}

Hereby, we would like to thank all the participants in this study for their cooperation. We appreciate Professor Susan Tebb at Saint Louis University for permission to use the Caregiver well-being scale (14 items), cooperation in translation and for her review and approval of this paper. We also appreciate Rozhan Ghobadimoghadam at Middle East Technical University for improving the use of English in the manuscript. We are grateful for the financial support of Shiraz University of Medical Sciences in this research.

\section{Ethics approval and consent to participate}

The study was approved by the Institutional Human Ethics Committee of Shiraz University of Medical Sciences (IR.SUMS.REC.1398.574). All participants included in the study, signed an informed consent 
form on recruitment to the study. All procedures performed in this study were comply with the ethical standards of the institutional and national research committee and with the 1964 Helsinki declaration and its later amendments or comparable ethical standards.

\section{Consent for publication}

Not applicable.

\section{Availability of data and materials}

Data will not be shared because of the confidentiality of Psychotic patients and their families' data.

\section{Competing of interests}

The authors declare that they have no competing interests.

\section{Funding}

The funders had no role in the study design, data collection and analysis, decision to publish, or preparation of the manuscript.

\section{Authors' contributions}

S.B, LZ and M.R contributed to the study conception and design. Material preparation, data collection and data analysis were performed by S.B, L.Z, M.R, F.S, E.M and Z.H. The manuscript was written by S.B and L.Z. All authors read and approved the final manuscript.

\section{Authors' information}

${ }^{1}$ Student Research Committee, Community Based Psychiatric Care Research Center, Department of Nursing, School of Nursing and Midwifery, Shiraz University of Medical Sciences, Shiraz, Iran. ${ }^{2,3,6}$ Community Based Psychiatric Care Research Center, department of Nursing, School of Nursing and Midwifery, Shiraz University of Medical Sciences, Shiraz, Iran. ${ }^{4}$ Community Based Psychiatric Care Research Center, Shiraz University of Medical Sciences, Shiraz, Iran. ${ }^{5}$ Department of Psychiatry, School of Medicine, Research Center for Psychiatry and Behavior Science, Ebnesina Hospital, Shiraz University of Medical Sciences, Shiraz, Iran.

\section{References}

1. Clifton NE, Hannon E, Harwood JC, Di Florio A, Thomas KL, Holmans PA, et al. Dynamic expression of genes associated with schizophrenia and bipolar disorder across development. Transl Psychiatry. 2019;9(1):74. doi: 10.1038/s41398-019-0405-x

2. Association AP. Diagnostic and statistical manual of mental disorders (DSM-5®): American Psychiatric Pub; 2013. 
3. Awad AG, Voruganti LN. The burden of schizophrenia on caregivers: a review. Pharmacoeconomics. 2008;26(2):149-62. doi: 10.2165/00019053-200826020-00005

4. Ochoa S, Vilaplana M, Haro JM, Villalta-Gil V, Martínez F, Negredo MC, et al. Do needs, symptoms or disability of outpatients with schizophrenia influence family burden? Social psychiatry and psychiatric epidemiology. 2008;43(8):612-8. doi: 10.1007/s00127-008-0337-x

5. Millier A, Schmidt U, Angermeyer MC, Chauhan D, Murthy V, Toumi M, et al. Humanistic burden in schizophrenia: a literature review. J Psychiatr Res. 2014;54:85-93. doi:

10.1016/j.jpsychires.2014.03.021

6. von Kardorff E, Soltaninejad A, Kamali M, Eslami Shahrbabaki M. Family caregiver burden in mental illnesses: The case of affective disorders and schizophrenia - a qualitative exploratory study. Nord J Psychiatry. 2016;70(4):248-54. doi: 10.3109/08039488.2015.1084372

7. Rahmani F, Ranjbar F, Hosseinzadeh M, Razavi SS, Dickens GL, Vahidi M. Coping strategies of family caregivers of patients with schizophrenia in Iran: A cross-sectional survey. Int J Nurs Sci. 2019;6(2):148-53. doi: 10.1016/j.ijnss.2019.03.006

8. Hefford C, Abbott JH, Baxter GD, Arnold R. Outcome measurement in clinical practice: practical and theoretical issues for health related quality of life (HRQOL) questionnaires. Physical Therapy Reviews. 2011;16(3):155-67. doi: 10.1179/1743288X11Y.0000000004

9. Shiraishi N, Reilly J. Positive and negative impacts of schizophrenia on family caregivers: a systematic review and qualitative meta-summary. Soc Psychiatry Psychiatr Epidemiol. 2019;54(3):277-90. doi: 10.1007/s00127-018-1617-8

10. Gelkopf M, Roe D. Evaluating outcome domains assessing caregivers of individuals with mental illness: a review. Fam Process. 2014;53(1):150-74. doi: 10.1111/famp.12056

11. Tebb S. An aid to empowerment: a caregiver well-being scale. Health Soc Work. 1995;20(2):87-92. doi: $10.1093 / \mathrm{hsw} / 20.2 .87$

12. Berg-Weger M, Burkemper E, Tebb SS, Rubio DM. The Well-Being of Siblings Who Share Care: A Case Study. Journal of Gerontological Social Work. 2001;35(1):89-105. doi:

doi.org/10.1300/J083v35n01_07

13. Berg-Weger M, Rauch SM, Rubio DM, Tebb SS. Assessing the health of adult daughter former caregivers for elders with Alzheimer's disease. Am J Alzheimers Dis Other Demen. 2003;18(4):231-9. doi: $10.1177 / 153331750301800402$

14. Berg-Weger M, Rubio DM, Tebb SS. The Caregiver Well-Being Scale revisited. Health Soc Work. 2000;25(4):255-63. doi: 10.1093/hsw/25.4.255

15. Berg-Weger M, Rubio DM, Tebb SS. Depression as a mediator: Viewing caregiver well-being and strain in a different light. Families in Society. 2000;81(2):162-73. doi: doi.org/10.1606/10443894.1010

16. Berg-Weger M, Rubio DM, Tebb SS. Living with and caring for older family members: Issues related to caregiver well-being. Journal of Gerontological Social Work. 2000;33(2):47-62. doi: doi.org/10.1300/J083v33n02_04 
17. Demirtepe-Saygılı D, Bozo Ö. Perceived social support as a moderator of the relationship between caregiver well-being indicators and psychological symptoms. Journal of Health Psychology. 2011;16(7):1091-100. doi: 10.1177/1359105311399486

18. Fields NL, Xu L, Richardson VE, Parekh R, Ivey D, Calhoun M. Utilizing the Senior Companion Program as a platform for a culturally informed caregiver intervention: Results from a mixed methods pilot study. Dementia. 2019:1471301219871192. doi: 10.1177/1471301219871192

19. Rubio DM, Berg-Weger M, Tebb SS. Assessing the validity and reliability of well-being and stress in family caregivers. Social Work Research. 1999;23(1):54-64. doi: doi.org/10.1093/swr/23.1.54

20. Rubio DM, Berg-Weger M, Tebb SS, Parnell LA. Comparing the well-being of post-caregivers and noncaregivers. Am J Alzheimers Dis Other Demen. 2001;16(2):97-101. doi:

$10.1177 / 153331750101600213$

21. Rubio DM, Berg-Weger M, Tebb SS, Rauch SM. Validating a measure across groups: The use of MIMIC models in scale development. Journal of social service research. 2003;29(3):53-67. doi: doi.org/10.1300/J079v29n03_03

22. Tebb SS, Berg-Weger M, Rubio DM. The Caregiver Well-Being Scale: developing a short-form rapid assessment instrument. Health Soc Work. 2013;38(4):222-30. doi: 10.1093/hsw/hlt019

23. Ward-Griffin C, Keefe J, Martin-Matthews A, Kerr M, Brown JB, Oudshoorn A. Development and validation of the double duty caregiving scale. Can J Nurs Res. 2009;41(3):108-28.

24. Beaton DE, Bombardier C, Guillemin F, Ferraz MB. Guidelines for the process of cross-cultural adaptation of self-report measures. Spine (Phila Pa 1976). 2000;25(24):3186-91. doi: 10.1097/00007632-200012150-00014

25. Beaton D, Bombardier C, Guillemin F, Ferraz MB. Recommendations for the cross-cultural adaptation of the DASH \& QuickDASH outcome measures. Institute for Work \& Health. 2007;1 (1):1-45.

26. Polit DF, Yang F. Measurement and the measurement of change: a primer for the health professions: Wolters Kluwer Health; 2015.

27. Waltz CF, Strickland OL, Lenz ER. Measurement in nursing and health research: Springer publishing company; 2010.

28. Novak M, Guest C. Application of a multidimensional caregiver burden inventory. Gerontologist. 1989;29(6):798-803. doi: 10.1093/geront/29.6.798

29. Abbasi A, Asayesh H, Rahmani H, Shariati A, Hosseini S, Rouhi G. The burden on cargivers from hemodialysis patients and related factors. Journal of Research Development in Nursing \& Midwifery. 2011;8(1):26-33.

30. Antonovsky A. Unraveling the mystery of health: new perspectives on mental and physical well being. San Francisco, CA: Jossey-Bass; 1987.

31. Eriksson M, Lindström B. Validity of Antonovsky's sense of coherence scale: a systematic review. Journal of Epidemiology \& Community Health. 2005;59(6):460-6. doi: 10.1136/jech.2003.018085 
32. Mahammadzadeh A, Poursharifi H, Alipour A. Validation of Sense of Coherence (SOC) 13-item scale in Iranian sample. Procedia-Social and Behavioral Sciences. 2010;5:1451-5. doi:

10.1016/j.sbspro.2010.07.306

33. Rohani C, Khanjari S, Abedi HA, Oskouie F, Langius-Eklöf A. Health index, sense of coherence scale, brief religious coping scale and spiritual perspective scale: psychometric properties. Journal of Advanced Nursing. 2010;66(12):2796-806. doi: 10.1111/j.1365-2648.2010.05409.x

34. Lawshe CH. A quantitative approach to content validity 1. Personnel psychology. 1975;28(4):563-75.

35. Polit DF, Beck CT, Owen SV. Is the CVI an acceptable indicator of content validity? Appraisal and recommendations. Research in nursing \& health. 2007;30(4):459-67.

36. Polit DF, Beck CT. The content validity index: are you sure you know what's being reported? Critique and recommendations. Research in nursing \& health. 2006;29(5):489-97.

37. Shi J, Mo X, Sun Z. [Content validity index in scale development]. Zhong Nan Da Xue Xue Bao Yi Xue Ban. 2012;37(2):152-5. doi: 10.3969/j.issn.1672-7347.2012.02.007

38. Fayers PM, Machin D. Quality of life: the assessment, analysis and interpretation of patient-reported outcomes: John Wiley \& Sons; 2013.

39. DeVon HA, Block ME, Moyle-Wright P, Ernst DM, Hayden SJ, Lazzara DJ, et al. A psychometric toolbox for testing validity and reliability. Journal of Nursing scholarship. 2007;39(2):155-64. doi: 10.1111/j.1547-5069.2007.00161.x

40. Sijtsma K. Reliability beyond theory and into practice. Psychometrika. 2009;74(1):169. doi: 10.1007/s11336-008-9103-y

41. Demirtepe D, Bozo Ö. Caregiver Well-being Scale: A study of validity and reliability. Turkish Psychological Articles. 2009;12(23):28-37.

\section{Supplementary Files}

This is a list of supplementary files associated with this preprint. Click to download.

- CWBSEnglishoriginalandpersianversion.docx

- Manuscript.docx 